\title{
The feasibility and advantages of laparoscopic surgery for ectopic pregnancy at a secondary hospital in South Africa
}

\author{
D Armatas, ${ }^{1} \mathrm{MB} \mathrm{ChB}$; G B Theron, ${ }^{2} \mathrm{MB} \mathrm{ChB}, \mathrm{MCOG}, \mathrm{MMed}(\mathrm{O} \& \mathrm{G}), \mathrm{BSc}$ Hons (Epidemiol), MD; \\ R Aronius, ${ }^{2} \mathrm{MB} \mathrm{ChB}$, MMed $(\mathrm{O} \& \mathrm{G})$ \\ ${ }^{1}$ Department of Obstetrics and Gynaecology, Faculty of Health Sciences, Stellenbosch University and Tygerberg Hospital, Cape Town, South Africa \\ ${ }^{2}$ Department of Obstetrics and Gynaecology, Worcester Provincial Hospital, Worcester, South Africa
}

Corresponding author: D Armatas (darmatas@yahoo.com)

\begin{abstract}
Background. Ectopic pregnancy (EP) is a gynaecological emergency with implications for maternal morbidity worldwide. Laparoscopic surgery is the preferred method of surgical management in most cases, as it has been shown to improve patient outcomes and overall care and to be cost effective and efficient.

Objectives. To investigate the feasibility of laparoscopic surgery for EP management at a secondary hospital, based on incidence rates and comparing surgery-associated variables and outcomes with those in laparotomy.

Methods. A retrospective study design was used. All patients who were treated surgically for EP at the Worcester Provincial Hospital were included. The required sample size was 81 . Data were collected from patient files and theatre reports. Cases were assigned to one of two cohorts based on the method of surgical management.

Results. A total of 84 cases were identified, of which 48 (57.1\%) were managed laparoscopically and 36 (42.9\%) with laparotomy. The average surgical time was 34.6 minutes and 44.9 minutes for a laparotomy and a laparoscopy, respectively. Patients who were treated laparoscopically required significantly less postoperative pain relief and had shorter hospital stays.

Conclusion. This study shows not only that laparoscopy treatment is a feasible option for EP in a secondary-hospital setting in South Africa, but also that the intervention is associated with significantly better patient outcomes than laparotomy. The demonstrated benefits make laparoscopy the preferred treatment modality for EP when surgical intervention is required.
\end{abstract}

S Afr J Obstet Gynaecol 2019;25(2):44-48. https://doi.org/10.7196/SAJOG.2019.v25i2.1445

An ectopic pregnancy (EP) results from the implantation of a fertilised ovum outside the uterus. ${ }^{[1]} \mathrm{EP}$ is one of the major causes of maternal morbidity and mortality worldwide. ${ }^{[2]}$ A 2017 report based on confidential enquiries into maternal deaths in South Africa (SA) shows that maternal deaths caused by EP have increased from $2.5 \%$ in 2011 to $3.4 \%$ in $2017 .^{[3]}$

Risk factors include a previous EP, during which treatment had been conservative, tubal pathology, previous genital infections, having multiple sexual partners, use of intrauterine devices, smoking, in vitro fertilisation and age. ${ }^{[1]}$ Chlamydia infection has been shown to be strongly associated with pelvic infections and thus increases the risk of EP.

EP should be a differential diagnosis in all women who present with vaginal bleeding or lower abdominal pain in the case of a positive pregnancy test. ${ }^{[4]}$ Early diagnosis makes conservative treatment possible and minimises morbidity and mortality. ${ }^{\left[{ }^{[j}\right]}$ Tubal rupture can result in life-threatening haemorrhage and shock, which should be approached with urgent surgical management. ${ }^{[4]}$

Treatment can be either surgical or non-surgical. Surgical treatment can involve either laparotomy or laparoscopy, whereas non-surgical treatment can be either expectant or medical. ${ }^{[6]}$ Treatment options depend on gestational age, evidence of rupture and requirements for future fertility. ${ }^{[2]}$

Transvaginal ultrasound and serial beta-human chorionic gonadotropin measurements allow early diagnosis, leading increasingly to medical management with methotrexate and minimally invasive surgery. ${ }^{[7]}$

The Royal College of Obstetrics and Gynaecology (RCOG) recommends a laparoscopic approach to surgical management, even in the case of a ruptured EP, if the operator is experienced..$^{[8]}$ The benefits of laparoscopic surgery were described in a systematic review of randomised trials that compared laparoscopic salpingostomy with an open surgical approach. Laparoscopic salpingostomy was associated with a significantly shorter procedure time (73 minutes v. 88 minutes), less perioperative blood loss ( $79 \mathrm{~mL}$ v. $195 \mathrm{~mL}$ ), shorter postoperative hospital stay ( 1 - 2 days v. 3 - 5 days) and shorter follow-up time (11 days v. 24 days) than open surgery. ${ }^{[9]}$

A retrospective audit of surgically managed EPs over a 5-year period at the Cleveland Clinic, Ohio, showed that $84.3 \%$ of patients were successfully managed with laparoscopic surgery, without any major intra- or postoperative complications. The study affirmed the benefits of a laparoscopic procedure and highlighted its safety and efficiency for overall patient care. ${ }^{[10]}$ The Cochrane review on EPs also notes that a laparoscopic approach is significantly less costly than open surgery. ${ }^{[11]}$

A clinical audit over a 30-month period at a district hospital in the UK showed similarly encouraging findings, with $62 \%$ of all patients diagnosed with EP managed laparoscopically. The audit also showed that laparoscopic management was safe and could be performed effectively in a district-hospital setting, with notable advantages 
including shorter hospital stays and reduced postoperative opiate requirement. ${ }^{[12]}$

There have been a number of systematic reviews following the management of tubal EP by either salpingostomy or salpingectomy. The RCOG notes that there is no clear evidence that salpingotomy should be used in preference to salpingectomy if a healthy contralateral tube is present. ${ }^{[8]}$ However, in the case of contralateral tubal disease, the RCOG advises that laparoscopic salpingotomy should be considered as primary treatment if future fertility is desired. ${ }^{[13]}$

The complication rate of laparoscopic surgery is low. Up to $50 \%$ of complications occur at first insertion of the abdominal port, during which entry is blind. Complications can also arise from abdominal insufflation, tissue dissection and disrupted haemostasis. Conversion to an open procedure may be necessary to manage complications. Complications such as vascular injury and bowel perforation can lead to severe morbidity or mortality. ${ }^{[14]}$

The primary objective of this study was to investigate the feasibility of laparoscopic surgery for EP in a secondary-hospital setting in SA. The study aimed to determine the proportion of laparoscopy compared with laparotomy from all surgically managed EPs. Secondary objectives involved the comparison of several variables in the two approaches to assess whether laparoscopy was a feasible method for surgical management in our setting.

\section{Methods}

A retrospective audit of 2 years' records (1 January 2015 - 31 December 2016) was performed at the Worcester Provincial Hospital (WPH), a secondary hospital in the Western Cape province, SA. Doctors of various experience levels work at this centre.

All patients who presented with suspected EP and received surgical management at WPH were included. Patients referred to WPH for management of complications following surgical treatment at another facility were excluded.

During data analysis, multivariate logistics regression was used to account for any confounding variables. If a patient's folder notes could not be found, but theatre reports and electronic records were available, the patient was eligible for inclusion in the study. As the information from the theatre notes met the criteria of our primary objective, these cases allowed partial information to be used.

A sample size of at least 81 patients was required. This was based on an incident rate of $50 \mathrm{EP}$ patients per year in the two previous years and an estimated underlying event rate of $60 \%-80 \%$ for EP-associated laparoscopy.

All doctors at our unit received consultant-supervised training in performing two- and three-port laparoscopic procedures. Once sufficiently skilled in performing the procedure safely, the doctor was allowed to operate without supervision. This applied to doctors across all levels of experience, from interns to registrars.

Data were collected from the electronic database of all surgeries at WPH. EP procedures were identified using the search terms 'indication' and 'ectopic pregnancy' and the respective ICD-10 codes for laparoscopy and laparotomy. Identified cases were crossreferenced with the theatre record book, which holds a handwritten record of all surgeries performed. We then used patients' folder numbers and full names to obtain their files from records.

Participants were assigned to one of two groups based on the method of surgical management (laparoscopy or laparotomy). Data on a number of other variables were also captured and entered into a data sheet for each cohort. The totals were tallied and compared.

Data were analysed using biomedical statistics software (Stata 14). Parametric data were described using means and 95\% confidence intervals, whereas medians, ranges and quartiles were used to describe non-parametric data. Chi-squared tests, odds ratios and standard deviations were used to compare frequencies. A significance level of $p<0.05$ was used. Independent-sample $t$-tests were used to compare normally distributed variables, whereas Mann-Whitney $U$ tests were used for comparison in non-parametric data sets. Logistic regression was used to account for possible confounding variables, such as loss of files, negative findings and incorrect information.

\section{Ethical approval}

Ethical approval was granted by both the Human Research Ethics Committee of the Faculty of Health Sciences, Stellenbosch University and the Provincial Research Ethics Committee (ref. no. S16/09/163). Confidentiality of patient information was maintained throughout the study.

\section{Results}

A total of 84 cases were identified, 42 each from 2015 and 2016. Theatre notes were available for all 84 patients, but only 71 full patient files were available. Data for age, post-surgery haemoglobin level and length of hospital stay were normally distributed, whereas data for gravidity, parity and estimated gestational age showed skewed distributions (Table 1). Means and associated standard deviations (SD) for age, post-surgery haemoglobin level and length of hospital stay were 28.5 (5.6) years, 9.9 (2) g/dL and 2.9 (0.9) days, respectively.

Records of previous EP and miscarriage were found for eight and nine patients, respectively. Comorbidities included pulmonary tuberculosis $(n=2)$ and asthma $(n=1)$ and $20 \%$ of the sample were HIV positive.

Table 1. Summary of variable ranges across study sample

\begin{tabular}{|c|c|c|c|c|c|c|c|c|c|}
\hline Parameter & $\begin{array}{l}\text { Age } \\
\text { (years) }\end{array}$ & Gravidity & Parity & $\begin{array}{l}\text { Estimated gestational } \\
\text { age (weeks) }\end{array}$ & $\begin{array}{l}\text { Surgical } \\
\text { time (min) }\end{array}$ & $\begin{array}{l}\text { Blood loss } \\
(\mathrm{mL})\end{array}$ & $\begin{array}{l}\text { Hb level pre } \\
\text { surgery }(\mathrm{g} / \mathrm{dL})\end{array}$ & $\begin{array}{l}\text { Hb level post } \\
\text { surgery }(\mathrm{g} / \mathrm{dL})\end{array}$ & $\begin{array}{l}\text { Hospital } \\
\text { stay (days) }\end{array}$ \\
\hline Minimum & 15 & 1 & 0 & 2 & 15 & 0 & 3.7 & 4.9 & 1 \\
\hline $\mathrm{P} 25^{*}$ & 25 & 2 & 0 & 6 & 25 & 100 & 9.4 & 8.3 & 2 \\
\hline P50* & 29 & 3 & 1 & 8 & 30 & 500 & 10.3 & 10.1 & 3 \\
\hline P75* & 33 & 3 & 2 & 8 & 60 & 725 & 11.9 & 11 & 3 \\
\hline Maximum & 42 & 8 & 7 & 18 & 120 & 2500 & 14.4 & 15.2 & 6 \\
\hline
\end{tabular}


Laparoscopy was performed in 48 cases (57.1\%) and laparotomy in 36 cases (42.9\%). Three laparoscopy cases were converted to laparotomies owing to blood in the abdomen causing poor visualisation. In four of the laparoscopy cases, no evidence of an EP was found.

Day hours are considered to be from 08h00 to $16 \mathrm{~h} 00$ on weekdays, during which a full staff complement is present. After-hours times are considered to be from $16 \mathrm{~h} 00$ to $08 \mathrm{~h} 00$ on weekdays and all hours of weekends and public holidays. After hours only one doctor is on call for each department and a full complement of theatre staff for one emergency theatre. Consultants are available off site. According to these definitions, 46 (54.8\%) of the surgeries were performed during day hours $(p<0.0001)$, of which $91.3 \%$ were laparoscopies and only $8.7 \%$ were laparotomies. Of the 38 procedures (45.2\%) performed after hours, $15.8 \%$ were laparoscopies whereas $84.2 \%$ involved open surgery $(p<0.0001)$.

When procedure type was categorised according to clinical skill level (Fig. 1; also see Table 2 for definitions), results showed that a consultant handled significantly more laparoscopic cases than clinicians from the other skill levels $(p<0.0001)$. Laparotomy cases were performed mostly by grade 1 medical officers and community service medical officers (Fig. 1).

Records of ruptured EPs were found for 66 cases $(78.6 \%)(p=0.15)$. Of these patients, 35 (53\%) received laparoscopic management and 31 (47\%) were treated by means of a laparotomy. In cases without rupture, $72.2 \%$ were managed laparoscopically; laparotomies were performed in the remainder of these cases.

Tables 3 and 4 show summary statistics for laparotomy $(N=36)$ and laparoscopy $(N=48)$, respectively. No significant differences were found for age $(p=0.7)$, gravidity $(p=0.6)$ or parity $(p=0.7)$ between the two treatment groups. Pre- and post-surgery haemoglobin levels also did not differ significantly between the two groups ( $p=0.6$ and $p=0.4$, respectively).

Significant differences were found in surgical time, blood loss and length of hospital stay between the two treatment groups. Mean surgical time (in minutes) for laparotomies (34.6 (23.1); range 15 - 120) was significantly less $(p=0.001)$ than for laparoscopic procedures (44.9 (19.2); range 20 - 115). Laparotomies were associated with significantly higher blood loss (712.5 (594.9) $\mathrm{mL}$ ) than laparoscopies (386.5 (394.2) $\mathrm{mL}) \quad(p=0.001)$. Hospital stay was significantly shorter $(p<0.0001)$ in laparoscopy patients (2.5 days) than in laparotomy patients (3.6 days).

A comparison of analgesic use in the two treatment groups is shown in Fig. 2. Analgesics included opioids (morphine) and oral analgesics (paracetamol and nonsteroidal anti-inflammatory agents). The average number of morphine doses (2.1) for the laparotomy group was significantly more $(p=0.04)$ than for the laparoscopy group (1.3). A similar trend was seen for oral analgesic dose (10.5 for the laparotomy group v. 4.3 for the laparoscopy group; $p=0.004$ ).

The number of blood transfusions was not significantly different between the two

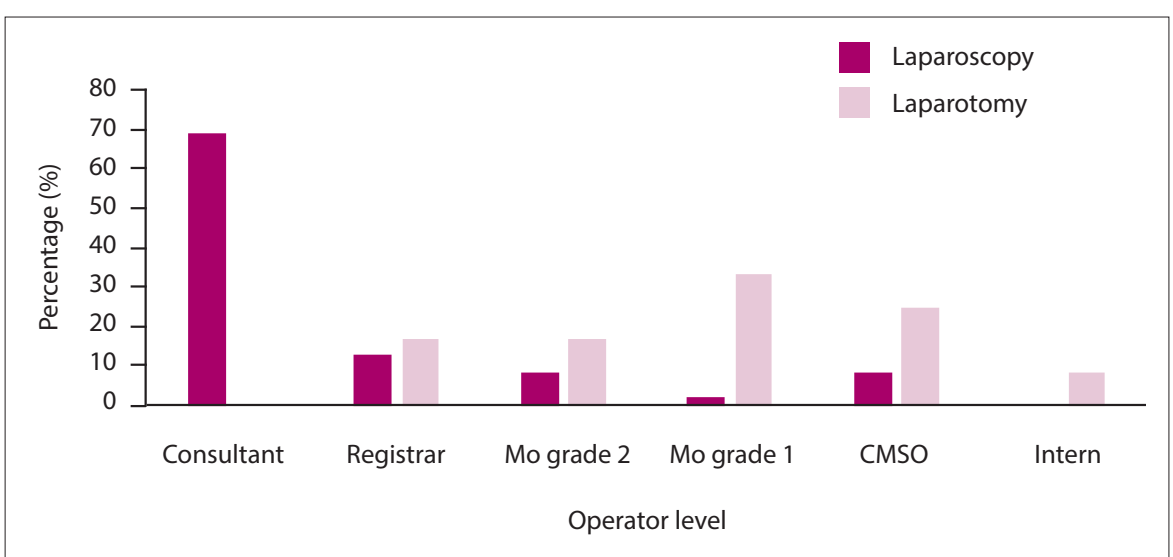

Fig. 1. Frequency of procedure type grouped according to operator level $(\mathrm{p}<0.0001)$.

( $M O=$ medical officer; $C S M O=$ community service medical officer. $)$

Table 2. Key to operator levels

\begin{tabular}{ll}
\hline Level & Description \\
\hline Consultant & Specialist \\
Registrar & Specialist in training \\
Medical officer grade 2 & Practising for $>5$ years \\
Medical officer grade 1 & Practising for $<5$ years \\
Community service medical & Completed internship; registered doctor \\
officer & \\
Intern & Completed medical school; now serving in supervised \\
& internship position
\end{tabular}

Table 3. Summary statistics of laparotomy cases $(N=36)$

\begin{tabular}{|c|c|c|c|c|c|c|c|c|c|}
\hline Parameter & $\begin{array}{l}\text { Age } \\
\text { (years) }\end{array}$ & Gravidity & Parity & $\begin{array}{l}\text { Estimated } \\
\text { gestational } \\
\text { age (weeks) }\end{array}$ & $\begin{array}{l}\text { Surgical time } \\
\text { (min) }\end{array}$ & $\begin{array}{l}\text { Hb level pre } \\
\text { surgery (g/dL) }\end{array}$ & $\begin{array}{l}\text { Hb level post } \\
\text { surgery (g/dL) }\end{array}$ & $\begin{array}{l}\text { Blood loss } \\
(\mathrm{mL})\end{array}$ & $\begin{array}{l}\text { Hospital stay } \\
\text { (days) }\end{array}$ \\
\hline $\mathrm{P} 25^{*}$ & 23 & 2 & 1 & 4 & 20 & 9.7 & 8.6 & 350 & 3 \\
\hline P50* & 29.5 & 2 & 1 & 6 & 30 & 10.3 & 10 & 500 & 3 \\
\hline $\mathrm{P}^{*} 5^{\star}$ & 33 & 3 & 2 & 8 & 37.5 & 11.5 & 10.7 & 1000 & 4 \\
\hline Maximum & 36 & 4 & 3 & 13 & 120 & 14 & 15.2 & 2500 & 6 \\
\hline Mean (SD) & $28.3(5.6)$ & $2.5(1)$ & $1.3(1)$ & $6.2(2.7)$ & $34.6(23.1)$ & $10.5(1.6)$ & $9.7(1.9)$ & $712.5(594.9)$ & $3.6(0.8)$ \\
\hline Cases included & 36 & $31^{\dagger}$ & $31^{\dagger}$ & $13^{\dagger}$ & 36 & $31^{\dagger}$ & $31^{\dagger}$ & 36 & $31^{\dagger}$ \\
\hline
\end{tabular}


RESEARCH

\begin{tabular}{|c|c|c|c|c|c|c|c|c|c|}
\hline Parameter & Age (years) & Gravidity & Parity & $\begin{array}{l}\text { Estimated } \\
\text { gestational } \\
\text { age (weeks) }\end{array}$ & $\begin{array}{l}\text { Surgical } \\
\text { time } \\
(\mathrm{min})\end{array}$ & $\begin{array}{l}\text { Hb level pre } \\
\text { surgery (g/ } \\
\text { dL) }\end{array}$ & $\begin{array}{l}\text { Hb level } \\
\text { post surgery } \\
(\mathrm{g} / \mathrm{dL})\end{array}$ & $\begin{array}{l}\text { Blood loss } \\
(\mathrm{mL})\end{array}$ & $\begin{array}{l}\text { Hospital } \\
\text { stay (days) }\end{array}$ \\
\hline Minimum & 15 & 1 & 0 & 3 & 20 & 3.7 & 6.5 & 0 & 1 \\
\hline $\mathrm{P} 25^{*}$ & 23 & 2 & 0 & 6 & 30 & 9.1 & 8.2 & 100 & 2 \\
\hline P50* & 29 & 3 & 1 & 8 & 42.5 & 10.9 & 10.4 & 250 & 2 \\
\hline $\mathrm{P} 75^{*}$ & 33 & 4 & 2 & 8 & 60 & 12.6 & 11.65 & 500 & 3 \\
\hline Maximum & 42 & 8 & 7 & 18 & 115 & 14.1 & 14.1 & 2000 & 5 \\
\hline Mean (SD) & $28.7(5.7)$ & $2.8(1.5)$ & $1.4(1.5)$ & $8.2(3.2)$ & $44.9(19.2)$ & $10.5(2.6)$ & $10(2)$ & $386.5(394.2)$ & $2.5(0.7)$ \\
\hline Cases included & 48 & $39^{+}$ & $39^{+}$ & $29^{+}$ & 48 & $40^{+}$ & $40^{+}$ & $48^{\dagger}$ & $40^{*}$ \\
\hline
\end{tabular}

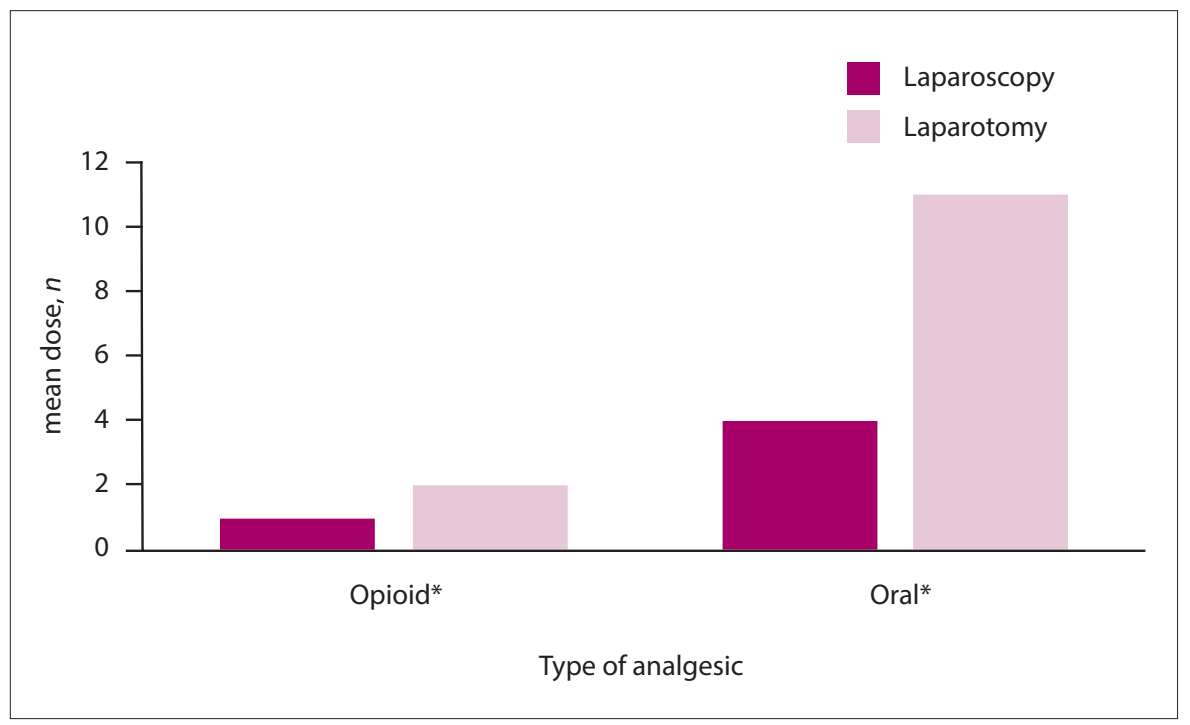

Fig. 2. Analgesic use per surgical group.

surgical groups $(p=0.8)$. Only one patient in the laparotomy group required two units of fresh frozen plasma $(p=0.3)$.

In total, four complications occurred: three in laparotomy patients (one case of sepsis and two cases of postoperative haemorrhage) and one in a laparoscopy patient (urinary retention).

\section{Discussion}

We identified 84 cases from the 2 years' records (42 cases per year), which exceeded the minimum requirement of 81 for adequate statistical power. Electronic theatre reports were found for all 84 cases, but complete patient files with complementary handwritten notes were available for only 71 cases, possibly owing to human error (e.g. incorrect identification or filing of records). Despite some consequent bias in the summary data, adequate data were available in the theatre records to allow us to fulfil our primary study objective (i.e. determining the rate of laparoscopy v. laparotomy for EP).
Results showed a laparoscopy rate of $57.1 \%$ compared with $42.9 \%$ for laparotomy, which is in keeping with international literature.

We also found that laparoscopic surgeries were preferentially performed during daytime hours. This may have been due to factors such as a consultant, with high-level surgical skill, being on duty during the day or a patient being stable enough to delay surgery until daytime hours. Junior doctors on duty after hours may not have had the experience and skill to perform laparoscopic procedures safely and may have felt more confident performing open surgery when a consultant was not available on site.

Consultants preferentially opted for laparoscopic management compared with junior doctors; as safe laparoscopy requires advanced training and surgical skill, this is not an unexpected finding. However, from the results in Fig. 1, it is evident that junior doctors are indeed being taught these skills and that they are performing laparoscopic management of EPs, albeit still in limited cases.
The majority of cases were found to be ruptured (79\%), as defined by blood being visible in the abdomen at surgical entry and required urgent treatment. However, in four unruptured cases, where the patients would have been stable enough to qualify for less invasive laparoscopic management, laparotomy proceeded instead owing to a junior doctor being on call, unable to offer laparoscopic surgery. Our study further suggests that the presence of blood in the pouch of Douglas in a haemodynamically stable patient is not a contraindication to laparoscopic surgery for ectopic pregnancy. ${ }^{[8]}$

Patients who were treated laparoscopically required significantly less analgesia, showed less blood loss and spent fewer days in hospital than those who received open surgery. Although laparoscopic surgery took, on average, $\sim 13$ minutes longer than a laparotomy and was found to be a statistically significant difference, the difference is deemed small and does not outweigh the cost benefits of laparoscopy, both for the patient and for the hospital. The complication rate was low in the laparoscopy group, with only one patient presenting with urinary retention postoperatively.

\section{Conclusion}

This study suggests that with the right training programme and equipment in place, laparoscopy treatment rates comparable to those seen in high-income countries are possible. In addition, laparoscopy appears to be a feasible treatment option for EP in our setting and is associated with significantly better outcomes for the patient with regard to pain management and hospital stay. The benefit of laparoscopy makes this the treatment modality of choice when surgical intervention for EP is required. Shorter hospital stays and less analgesic use also reduce costs for the hospital. We recommend 


\section{RESEARCH}

that laparoscopic training and equipment be made available in all hospitals in SA to provide EP patients with optimal surgical treatment.

Acknowledgements. None.

Author contributions. Equal contribution.

\section{Funding. None}

Conflicts of interest. None.

1. Tulandi T. Ectopic pregnancy: Epidemiology, risk factors and anatomical sites. https://www uptodate.com/contents/ectopic-pregnancy-epidemiology-risk-factors-and-anatomic-sites (accesse 22 July 2016).

2. Farquhar CM. Ectopic pregnancy. Lancet 2005;366(9485):583-591. https://doi.org/10.1016/S01406736(05)67103-6

3. Department of Health (DoH). Saving Mothers 2017: Seventh report on the Confidential Enquiries into Maternal Deaths in South Africa revised 2017. Pretoria: DoH, 2018. www.health.gov.za (accessed 19 Septemer 2019).

4. Walker JJ. Ectopic pregnancy. Clin Obstet Gynecol 2007;50(1):89-99. https://doi.org/10.1097/ GRF.0b013e31802f4f79

5. Moawad NS, Mahajan ST, Moniz MH, Taylor SE, Hurd WW. Current diagnosis and treatment of interstitial pregnancy. Am J Obstet Gynecol 2010;202(1):15-29. https://doi.org/10.1016/. jmig.2009.08.388
6. Stock L, Milad M. Surgical management of ectopic pregnancy. Clin Obstet Gynecol 2012;55(2):448454. https://doi.org/10.1097/GRF.0b013e3182510a19.

7. Cooray H, Harilall M, Farquhar CM. A six-year audit of the management of ectopic pregnancyAust N Z J Obs Gynaecol 2002;42(5):538-542. https://doi.org/10.1111/j.0004-8666.2002.00538.x

8. Elson CJ, Salim R, Potdar N, Chetty M, Ross JA, Kirk E on behalf of the Royal College of Obstetricians and Gynaecologists. Diagnosis and management of ectopic pregnancy. BJOG 2016;123:e15-e55. https://doi.org/10.1111/1471-0528.14189

9. Tulandi T. Ectopic pregnancy: Choosing a treatment. https://www.uptodate.com/contents/ectopicpregnancy-choosing-a-treatment (accessed 22 July 2016).

10. Mohamed H, Maiti S, Phillips G. Laparoscopic management of ectopic pregnancy: A 5-year experience. J Obs Gynaecol 2002;22(4):411-414. https://doi.org/10.1080/01443610220141399

11. Hajenius PJ, Mol F, Mol BWJ, Bossuyt PMM, Ankum WM, Van der Veen F. Interventions for tubal ectopic pregnancy. Cohrane Database Syst Rev 2007;1:CD000324. https://doi.org/10.1002/14651858. CD000324.pub2

12. Olagundoye V, Adeghe J, Guirguis M, Cox C, Murphy D. Laparoscopic surgical management of ectopic pregnancy: A district general hospital experience. J Obs Gynaecol 2000;20(6):620-623. https://doi.org/10.1080/01443610020001495

13. Capmas P, Bouyer J, Fernandez H. Treatment of ectopic pregnancies in 2014: New answers to som old questions. Fertil Steril 2014;101(3):615-620. https://doi.org/10.1016/j.fertnstert.2014.01.029

14. Pryor A, Mann Jr WJ, Bates AT. Complications of laprascopic surgery. https://www.uptodate.com/ contents/complications-of-laparoscopic-surgery (accessed 22 July 2016).

Accepted 18 August 2019. 